\title{
Mechanical Behaviour Modelling of an Mg-Stabilized Zirconia Reinforced TRIP-Matrix-Composite under Cold Working Conditions
}

\author{
Sergey Guk ${ }^{1}$, Wolfhart Müller ${ }^{1}$, Katja Pranke1, Rudolf Kawalla, ${ }^{1,2}$ \\ ${ }^{1}$ Institute for Metal Forming, TU Bergakademie Freiberg, Freiberg, Germany \\ ${ }^{2}$ Department of Plastic Deformation of Special Alloys, National University of Science and Technology MISIS, \\ Moscow, Russia \\ Email: sergey.guk@imf.tu-freiberg.de
}

Received 12 July 2014; revised 11 August 2014; accepted 26 August 2014

Copyright @ 2014 by authors and Scientific Research Publishing Inc.

This work is licensed under the Creative Commons Attribution International License (CC BY). http://creativecommons.org/licenses/by/4.0/

(c) (7) Open Access

\begin{abstract}
In the present work, a new method to predict the stress-strain curves for three-phase materials has been developed. It was applied using the example of an Mg-stabilized zirconia reinforced TRIP-matrix-composite. The content of the ceramic phase was varied between $5 \%$ and $20 \%$, whereas the particle size of the ceramic was selected to be 30 to $50 \mu \mathrm{m}$. The method is a further development of mixture rule for multiphase materials with more than two microstructure components. The prediction results were compared with the original method of mixture rule and with the IsoE-method. It is shown that the new method significantly improves the convergence compared to the standard method for mixture rule, even though it does not reach the accuracy of IsoE-method. Furthermore, there is an improvement of predicted convergence for large values of the total stress. Finally, a working map was designed for a quick graphical definition of the objective functions.
\end{abstract}

\section{Keywords}

Modelling, Mechanical Behaviour, Metal Matrix Composite, TRIP-Steel, $\mathrm{ZrO}_{2}$

\section{Introduction}

Mechanical behaviour modelling of multiphase-materials is an important field of physical metallurgy. Nowa-

How to cite this paper: Guk, S., Müller, W., Pranke, K. and Kawalla, R. (2014) Mechanical Behaviour Modelling of an MgStabilized Zirconia Reinforced TRIP-Matrix-Composite under Cold Working Conditions. Materials Sciences and Applications, 5, 812-822. http://dx.doi.org/10.4236/msa.2014.511081 
days, three main families of solving methods are available: the classical mixture rule, the self-consistent method and the finite element method.

The first mentioned family is widely used because of its very simple application. The two-phase microstructure can be displayed as an $\alpha$-matrix, with embedded $\beta$-structural components having globular, disc-shaped or cylindrical/rod-like morphology [1]. When forming a two-phase structure three areas can be distinguished (Figure 1):

1) The two phases are only elastically stressed;

2) The $\alpha$-phase is plastically deformed, and $\beta$ is still in the elastic deformation range;

3) Both phases are plastically deformed.

In the case of parallel load, on the left hand side, the same strain is applied to both phases causing a stress rise in the phase with the lower stress level. In the case of row load, the softer phase is stretched excessive (Figure 1, right hand side). According to Fischmeister and Karlsson the excessive ratio equals the ratio of the elastic moduli [2].

When one of the two phases entering the region of plastic deformation, the mathematical treatment is difficult. For this purpose the mixture rule has been proposed by Tamura et al. This was found to be a useful tool for describing the flow characteristics of two-phase structures. It was found to be:

$$
\begin{gathered}
\sigma_{\text {mix. }}=f_{\alpha} \cdot \sigma_{\alpha}\left(\varepsilon_{\alpha}\right)+f_{\beta} \cdot \sigma_{\beta}\left(\varepsilon_{\beta}\right) \\
\varepsilon_{\text {mix. }}=f_{\alpha} \cdot \varepsilon_{\alpha}+f_{\beta} \cdot \varepsilon_{\beta}
\end{gathered}
$$

where $f_{\alpha}$ and $f_{\beta}$ equal volume fraction of the phases $\alpha$ and $\beta$. The mixture rule postulated that the stresses, as well as the strains, can to be divided equal with the ratio of the volume fractions. This is graphically illustrated in Figure 2. With known stress-strain curves for $\alpha$ and $\beta$ component the stress-strain curve of the mixing microstructure can be determined graphically for a known expansion ratio $\varepsilon_{\alpha} / \varepsilon_{\beta}$. The dashed stress-strain curve in Figure 2 was constructed on the basis of the mixture rule by Tamura for the case $\varepsilon_{d} / \varepsilon_{\beta}=$ const. The points of the resulting stress-strain curve of $\alpha$ and $\beta$ were connected; this meant the corresponding strains $\varepsilon_{\alpha 1}$ with $\varepsilon_{\beta 1}$ and so on, till $\varepsilon_{\alpha n}$ was connected with $\varepsilon_{\beta n}$. On the dotted line the percentage of the volume fractions of the phases was marked and gave the resulting stress-strain curve of the mixed structure [2]. It is obvious that this modelling needs always a fitting parameter. Indeed, it should be noted that Equations (1) and (2) does not indicate anything about the absolute amount of the stress and strain transfer. This is the reason why several authors have proposed to define the following quantity (Figure 2):
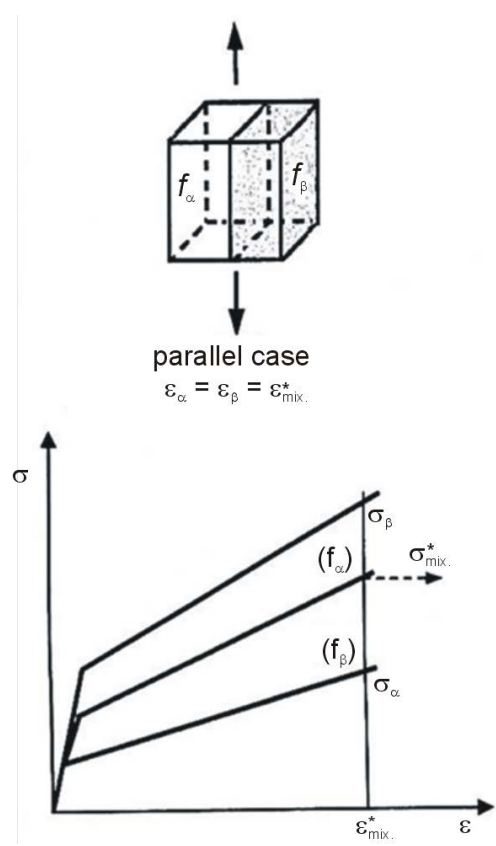

Figure 1. Distribution of stress and strain in a layer composite [1].
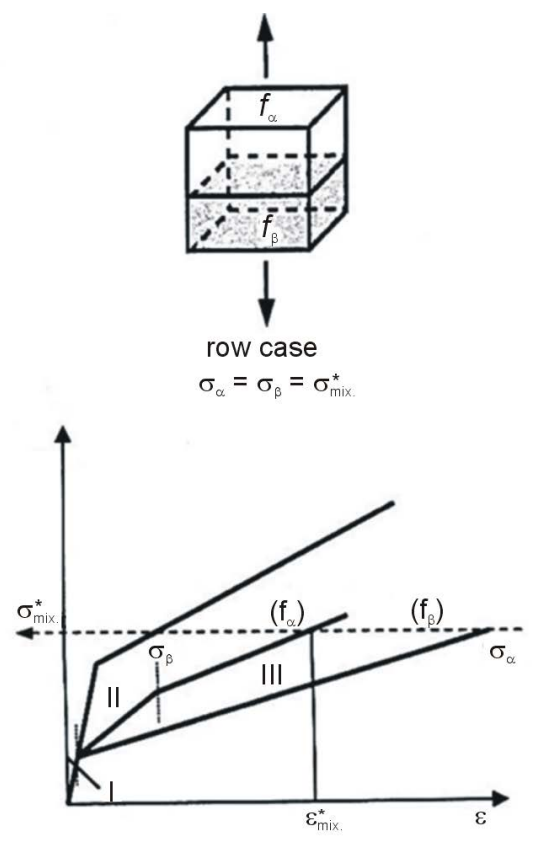

]. 


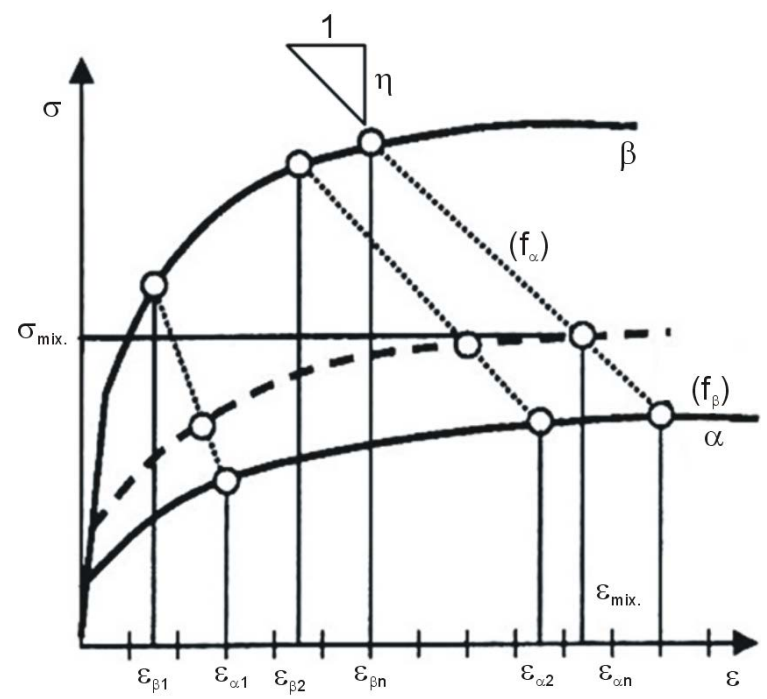

Figure 2. Distribution of stress and strain according to the rule of mixtures for two-phase composite [3].

$$
\eta=\frac{\sigma_{2}-\sigma_{1}}{\varepsilon_{2}-\varepsilon_{1}},
$$

where $\eta$ is an arbitrary fitting constant with $0 \leq \eta \leq \infty$ [4] [5]. The greater the value of $\eta$, the more closely does the situation approach parallel case condition. The row case condition is given for $\eta=0$. The exact nature of the dependence of $\eta$ with composite arrangement and microstructure is yet not clearly known. The major advantage of the mixture rule is that the stress-strain behaviour of two-phase microstructures can at least give a first approximation and is determined relatively easily. The problem of an accurate prediction of the stress-strain curve of the mixing structure is that the elongation ratio $\varepsilon_{\alpha} / \varepsilon_{\beta}$ for two phase constituents is already mostly unknown and has to be determined by elaborate experimental methods. For microstructures with more constituent phases the experimental effort increases tremendously. Therefore, there are no conceptions and approaches till now for the prediction of stress-strain curves of multi-phase materials by means of the mixture rule with the phase number greater than two.

The second family of the available solving methods for mechanical behaviour modelling of multiphase-materials is based on homogenisation techniques like the self-consistent method. This method is based on the fact that for a disordered microstructure, independent of the material state, the mechanical work increment-so called IsoW-method [6]—or energy density increment—so called IsoE-method [7]—can be equalized for each constituent. With other words the IsoW-method is expressed as follows:

$$
\sigma_{\text {mix. }} \cdot d \varepsilon_{\text {mix. }}=\sigma_{\alpha} \cdot d \varepsilon_{\alpha}=\sigma_{\beta} \cdot d \varepsilon_{\beta}=\cdots=\sigma_{n} \cdot d \varepsilon_{n} .
$$

The IsoE-method is expressed as:

$$
\int_{0}^{\varepsilon_{\text {mix. }}} \sigma_{\text {mix. }}(\varepsilon) d \varepsilon=\int_{0}^{\varepsilon_{\alpha}} \sigma_{\alpha}(\varepsilon) d \varepsilon=\int_{0}^{\varepsilon_{\beta}} \sigma_{\beta}(\varepsilon) d \varepsilon=\cdots=\int_{0}^{\varepsilon_{n}} \sigma_{n}(\varepsilon) d \varepsilon .
$$

The self-consistent method gives a more realistic description than the simple mixture rule on stress and has the advantage that no arbitrary fitting parameter is needed. The main disadvantage of the self-consistent method is the difficult calculation method. The third family of the available solving methods for mechanical behaviour modelling of multiphase-materials is based on finite element description of either a unit cell or a representative microstructure. It is able to be more accurate but much more difficult to perform, and therefore less used than the other two methods.

To prepare a procedure for the prediction of stress-strain curves of multi-phase materials with the phase number greater than two by means of the easy running mixture law, TRIP-matrix-composites with the different content of ceramic phase were used. The fitting parameters had to be determined according to the microstructure. 
For the modelling very densely sintered material with full stabilized ceramic fractions required. To keep the required effort for the determination of the elongation ratio $\varepsilon_{\gamma} / \varepsilon_{\mathrm{Ms}_{\mathrm{s}}} / \varepsilon_{\mathrm{ZrO}_{2}}$ low, it should be taken from the computed IsoE-method and validated with experimental results.

\section{Experimental Details}

The investigated material is based on two components, on the one hand there is a manganese-containing austenitic gas-atomized steel powder $\left(d_{10}=8 \mu \mathrm{m}, \mathrm{d}_{50}=20 \mu \mathrm{m}\right.$ and $\left.\mathrm{d}_{90}=127 \mu \mathrm{m}\right)$. On the other hand there is a powder of MgO-stabilized $\mathrm{ZrO}_{2}$ ceramic $\left(\mathrm{d}_{10}=25 \mu \mathrm{m}, \mathrm{d}_{50}=35 \mu \mathrm{m}\right.$ and $\left.\mathrm{d}_{90}=48 \mu \mathrm{m}\right)$. The chemical composition of the metastable high alloyed TRIP-steel (indicated as 16-7-6 with the nominal concentration of $\mathrm{Cr}$, $\mathrm{Mn}$ and $\mathrm{Ni}$ ), the stable austenitic steel AISI 316L [8] and the $\mathrm{ZrO}_{2}$ ceramic are shown in Table 1. The stable austenitic steel AISI 316L is needed for the modelling of own experimental results.

By varying the ceramic particle content three different powder mixtures were obtained. Therefore, the contents of ceramic particles in the steel matrix were given by $5 \%, 10 \%$ and $20 \%$. These mixtures were cold pre-compressed into disc form with a diameter of $155 \mathrm{~mm}$ and a height of $36 \mathrm{~mm}$ at a uniaxial pressure with 90 $\mathrm{MPa}$, and finally hot pressing sintered. The sintering was carried out under Varigon $\left(5 \% \mathrm{H}_{2}\right.$ and $\left.95 \% \mathrm{Ar}\right)$ atmosphere at $1250^{\circ} \mathrm{C}$ for $30 \mathrm{~min}$. The heating and cooling rates were $10 \mathrm{~K} / \mathrm{min}$, respectively. After that a set of specimens was selected for the metallographic examination and visualization of the particle distribution of the $\mathrm{ZrO}_{2}$ in a TRIP-steel matrix (Figures 3(a)-(c)). TRIP-steel regions are shown in light grey and the $\mathrm{ZrO}_{2}$ in dark grey. It is obvious that the particle distribution in the TRIP-steel matrix is nearly homogenous and there were no agglomerates found. The measurement of the phase composition of $\mathrm{ZrO}_{2}$ in the sintered state showed an absence of tetragonal phase modification.

The porosity of each sample was measured using the Archimedes method. It was observed that the samples are almost full dense with the values of the total porosity of at most $0.1 \%$. For this reason it was stated that the subsequent tests were conducted on compact material states.

The stress-strain curves of the single components of the composite-TRIP-steel 16-7-6, its stable austenitic variation AISI 316L, $\mathrm{ZrO}_{2}$ and strain-induced martensite-are illustrated in Figure 4. The datasets originate from different sources: TRIP-steel data are own investigations, ceramic data comes from the IKTS in Dresden, AISI 316L is part of [8] and martensite data are given in [9]. The expected results for the strain-induced martensite exhibits very good congruence with the results of [8].

Cold upsetting specimens of $9 \mathrm{~mm}$ in initial diameter and $16.2 \mathrm{~mm}$ in initial height, corresponding to an aspect ratio of 1.8, were prepared by machining from hot pressed discs. For the prediction of stress-strain curves of composites as well as the modelling of TRIP-kinetics during the cold forming the modified model of Pyshmintsev et al. was applied with the same deformation parameters [10]. In order to validate the kinetics of the $\alpha^{\prime}-$ martensite evolution for the TRIP-steel 16-7-6, the ferromagnetic phase fraction of the samples with different contents of ceramic particles were measured using magnetic balance testing and a previous calibration.

\section{Results and Discussion}

To forecast the flow properties of steels with TRIP-effect a model is required using plastic deformation considering martensite formation. Conducted cold upsetting tests allowed to calculate according to [11] the change of hydrostatic stress on the lateral surfaces of the specimens with different content of $\mathrm{ZrO}_{2}$. The results are presented in Figure 5, and the values of hydrostatic stress-despite their negative values-are in absolute value. The figure shows that the highest value of the hydrostatic compressive stress in the lateral surface of the sample is observed in the composite with $5 \% \mathrm{ZrO}_{2}$. These measurements are logically associated with the maximum

Table 1. Chemical composition of the steels and $\mathrm{ZrO}_{2}$ (content in wt\%).

\begin{tabular}{|c|c|c|c|c|c|c|c|}
\hline Steel alloy & $\mathrm{C}$ & Mn & $\mathrm{Si}$ & $\mathrm{Cr}$ & $\mathrm{Ni}$ & $\mathrm{N}$ & $\mathrm{Fe}$ \\
\hline 16-7-6 (metastable) & 0.03 & 7.2 & 1.00 & 16.3 & 6.6 & 0.09 & bal. \\
\hline AISI 316L (stable) & 0.03 & 1.9 & 0.26 & 17.4 & 14.7 & 0.08 & bal. \\
\hline \multirow[t]{2}{*}{ Ceramic } & $\mathrm{ZrO}_{2}$ & $\mathrm{MgO}$ & $\mathrm{Na}_{2} \mathrm{O}$ & $\mathrm{CaO}$ & $\mathrm{TiO}_{2}$ & $\mathrm{Fe}_{2} \mathrm{O}_{3}$ & $\mathrm{SiO}_{2}$ \\
\hline & 94.14 & 2.82 & 0.10 & 0.15 & 0.13 & 0.13 & 0.41 \\
\hline
\end{tabular}




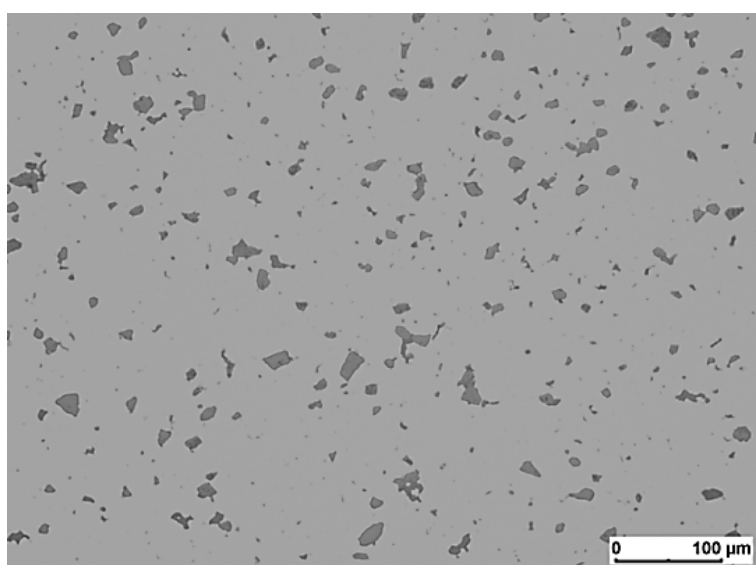

(a)

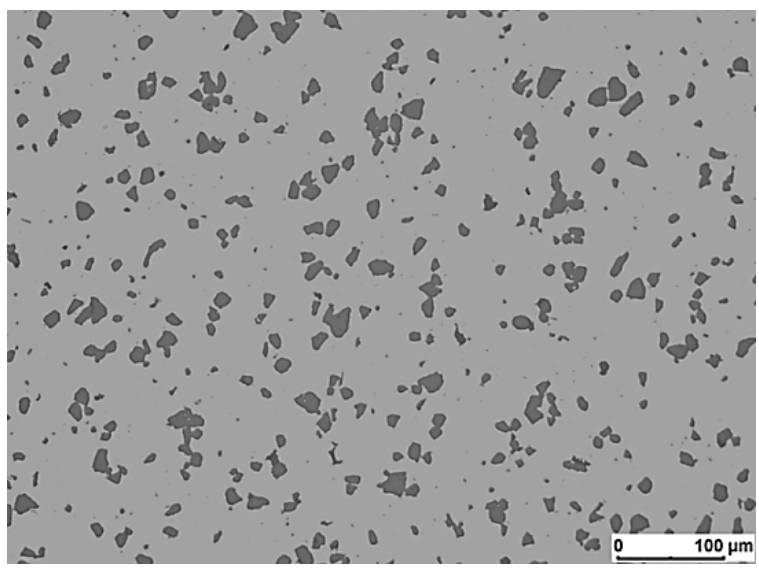

(b)

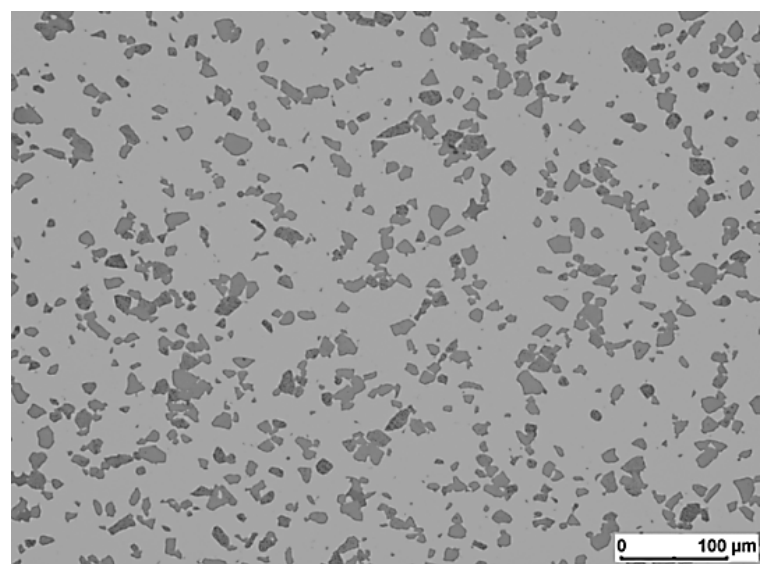

(c)

Figure 3. Distribution of second-phase particle of $\mathrm{ZrO}_{2}$ in TRIP-steel-5\% $\mathrm{ZrO}_{2}$ (a), TRIP-steel- $10 \%$ ZrO 2 (b) and TRIPsteel-20\% $\mathrm{ZrO}_{2}$ (c).

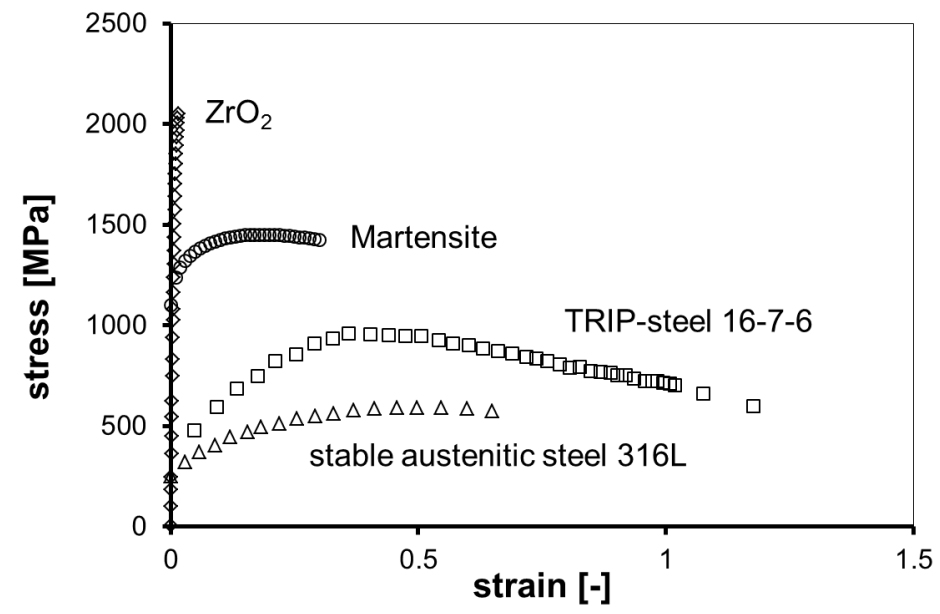

Figure 4. Compressive stress-strain curves of $\mathrm{ZrO}_{2}, \alpha^{\prime}$-martensite, TRIPsteel $16-7-6$ and a stable steel AISI $316 \mathrm{~L}$ at $20^{\circ} \mathrm{C}$.

values of the fracture limit strain for the studied materials. With increasing volume fraction of the ceramic content in the composite the absolute amount of compressive hydrostatic stress falls. Simultaneously the value of the fracture limit strain decreases. 


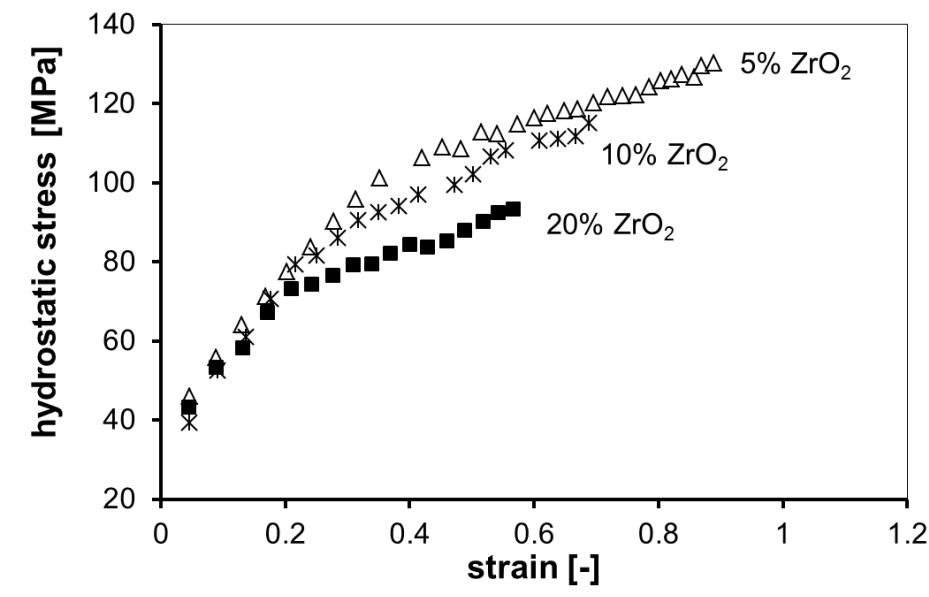

Figure 5. The variation of hydrostatic stress with respect to the total strain for different $\mathrm{ZrO}_{2}$ percentage.

To determine the amount of $\alpha^{\prime}$-martensite, transformed from metastable austenite during the TRIP-effect, the method according to [10] was used. Comparison of the calculated values of volume fraction of the retained austenite during deformation with some measured values for selected specimens after cold upsetting test is shown in Figure 6. The figure shows an excellent convergence of results in a fairly wide interval of values. On the basis of these calculations the possibility of quantitative prediction of the volume fraction of each phase was obtained at every step of deformation.

Based on the IsoE-method stress-strain curves of composites with different content of $\mathrm{ZrO}_{2}$ were determined (Figure 7(a)). Initially stress-strain curves of the phases and in the previous step calculated volume fraction of each of the three phases were needed. The figure shows that an increase of the volume fraction of $\mathrm{ZrO}_{2}$ leads to an insignificant increase in the level of stress, according to the calculation.

But the experimental validation was accurate only in the region of small strains. The convergence of calculated and experimentally determined values is shown in Figure 7(b). Consequently this method allows one to predict the value of the stress accurately at any step of deformation, although the calculated values are little bit lower compared to the experimental ones. The good convergence of calculated and experimental values tends to minimal reduction with increasing stress and decreasing volume fraction of $\mathrm{ZrO}_{2}$.

Based on the mixture rule, initial stress-strain curves of phases and calculated volume fraction of each of the three phases the stress-strain curves of composites with different content of $\mathrm{ZrO}_{2}$ were determined (Figure 8(a)). The figure shows that increasing the volume fraction of $\mathrm{ZrO}_{2}$ leads, according to calculation, to a larger increase in stress level than experimentally measured. The convergence of calculated values with the experimentally determined ones is shown in Figure 8(b). The convergence of this method is worse compared to the above IsoE (Figure 7(b)), particularly in the region of high stresses. The calculated values are either lower (5\% and 10\% $\left.\mathrm{ZrO}_{2}\right)$ or higher $\left(20 \% \mathrm{ZrO}_{2}\right)$ compared to the experimentally determined stresses.

To improve the convergence of calculation based on the mixture rule the accuracy of estimates of the total deformation of the composite has to be increased. The total deformation is determined by the Equation (2) using the values of local deformations of each of the phases and their volume fractions.

Because the experimental determination of local deformations is fraught with difficulties, the IsoE-method in inverse mode was used. The convergence with measured stresses is significantly better (see Figure 7(b)) than for the mixture rule (see Figure 8(b)). Based on this the relationship between the total strain of the composite and local deformation values of each of the phases was determined (Figure 9). The figure shows that the curves for each phase component are nonlinear. The deformation of austenite in the range of low total strain of composite corresponds substantially to the composite strain. With further increase of the total strain of composite the local deformation of austenite tends to higher strain values than the composite. The local deformation of martensite and $\mathrm{ZrO}_{2}$ is significantly lower than the total strain of composite.

Carrying out an inverse calculation of the total stress of the composite, according to IsoE-method, depending on the volume fraction of $\mathrm{ZrO}_{2}$ and the local deformation makes it possible to find a relationship depending on the other two variables: 


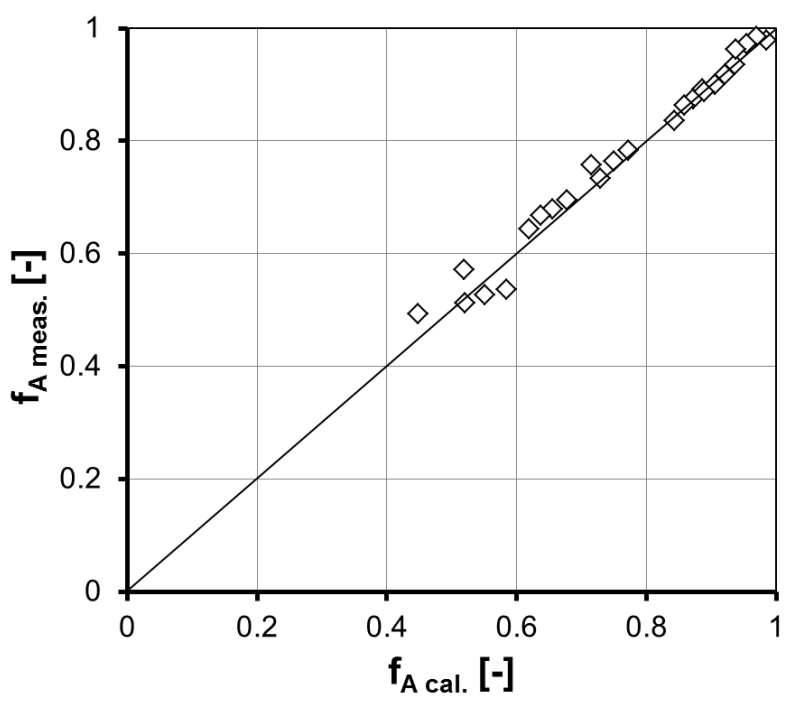

Figure 6. Convergence of the prediction for the values of volume fraction for retained austenite during deformation based on the modified model according to [10].

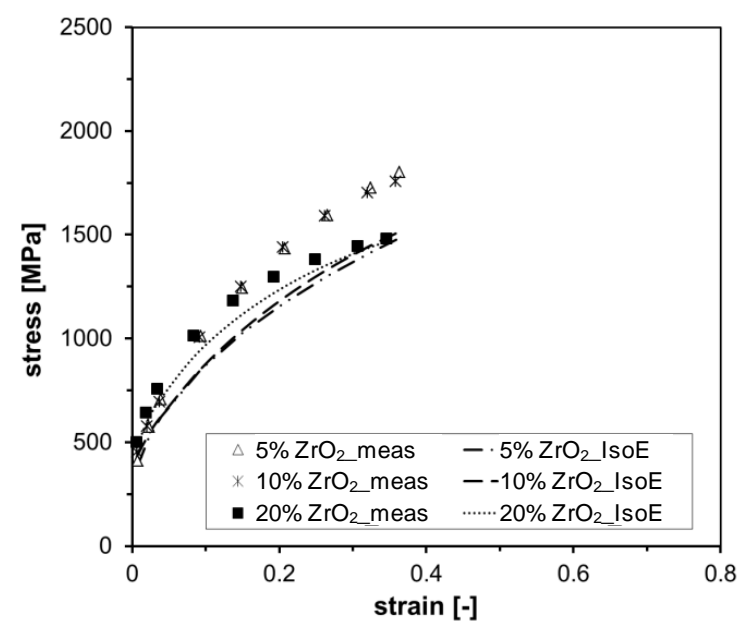

(a)

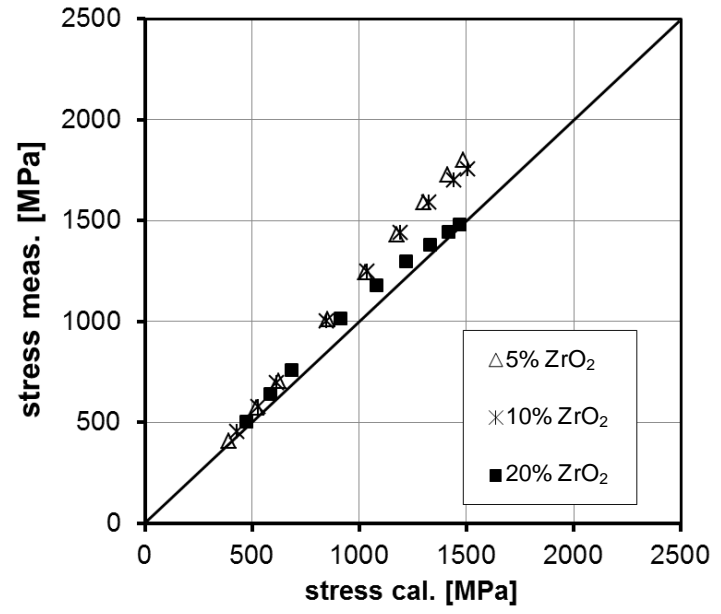

(b)

Figure 7. Predicted stress-strain curves according to the IsoE-method (a) and its convergence with the experiment (b).

$$
\varepsilon_{\mathrm{ZrO}_{2}}=\frac{0.00005 \cdot \sigma_{\text {mix. }}-0.02 \cdot f_{\mathrm{ZrO}_{2}}-0.005}{6.66 \cdot f_{\mathrm{ZrO}_{2}}-0.0009 \cdot \sigma_{\text {mix. }}+1}
$$

Concerning this relationship it is evident that depending on the total stress value of the composite the local deformation of $\mathrm{ZrO}_{2}$ can increase with decreasing of the volume fraction of $\mathrm{ZrO}_{2}$. This effect is explained by the fact that with a decrease in volume fraction of $\mathrm{ZrO}_{2}$ it is necessary to enlarge the total strain applied to the composite, and thus a large local deformation of $\mathrm{ZrO}_{2}$, to achieve the level of total stress. A comparison between calculated values of local deformation of $\mathrm{ZrO}_{2}$ according to the presented equation and the values defined with IsoE-method is illustrated in Figure 10. The figure shows an excellent convergence of the calculation results by means of this equation. This allows the use for further calculations.

The inverse analysis of the IsoE-method enables to combine the total strain of the composite and its three separate phases with the level of total and local stresses. Based on the obtained numerical array of data the relationship linking the total strain of the composite with the value of the local deformation $\mathrm{ZrO}_{2}$ and the level of total stress was determined: 


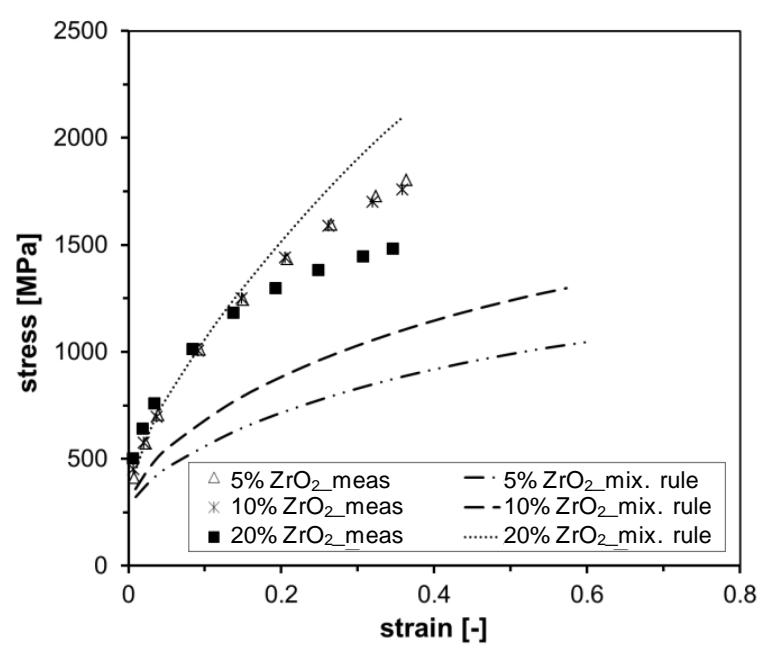

(a)

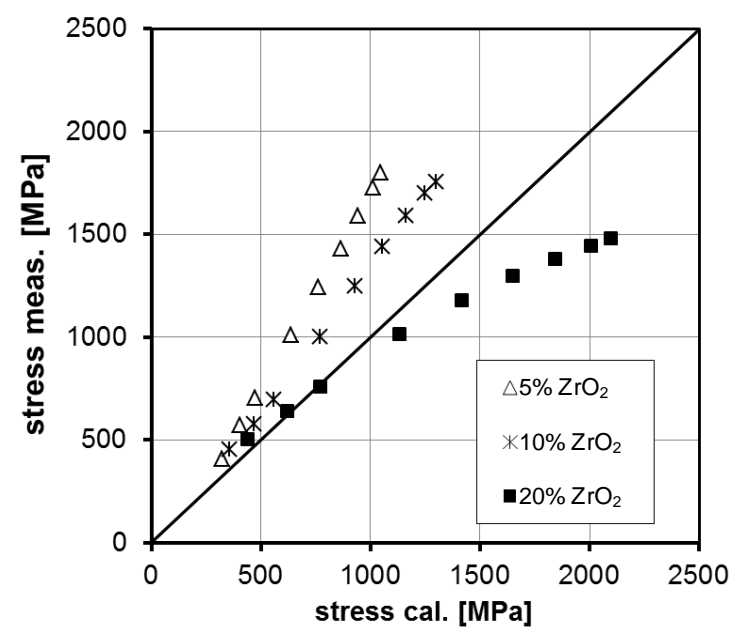

(b)

Figure 8. Predicted stress-strain curves according to the mixture rule (a) and its convergence with the experiment (b).

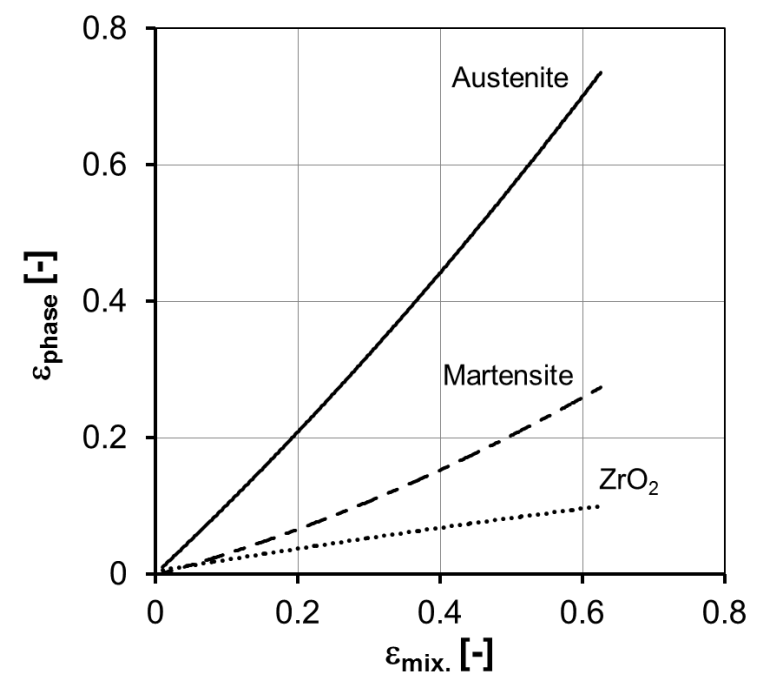

Figure 9. Relationship between the total strain of the composite and local deformation values of each phase within the composite.

$$
\varepsilon_{\text {mix. }}=e^{8.59-0.88 \cdot \ln \left(\sigma_{\text {mix. }}\right)+1.44 \cdot \ln \left(\varepsilon_{\mathrm{ZrO} 2}\right)}
$$

It is obvious that depending on the local deformation of $\mathrm{ZrO}_{2}$ the total strain of composite can increase with a decrease in the total stress. This is due to the fact that for one and the same local deformation of $\mathrm{ZrO}_{2}$ the value of total strain of composite will increase and the total stress will decrease with decreasing of volume fraction of $\mathrm{ZrO}_{2}$.

Using the proposed method of prediction for the total strain of the composite (see Equation (7)) and based on the mixture rule to determine the level of total stress (see Equation (1)) stress-strain curves for the investigated composites were determined (Figure 11(a)). The convergence of calculated values with the experimentally determined values is shown in Figure 11(b). A comparison of convergence of the three methods (see Figure 7(b), Figure 8(b) and Figure 11(b)) shows that the proposed method in this paper, even though it does not reach the accuracy of IsoE-method, significantly improves the convergence as compared to the standard method mixture rule. Furthermore Figure 11(b) illustrates that for the $\mathrm{ZrO}_{2}$ content of $20 \%$ there is an improvement of predicted convergence for large values of the total stress. 


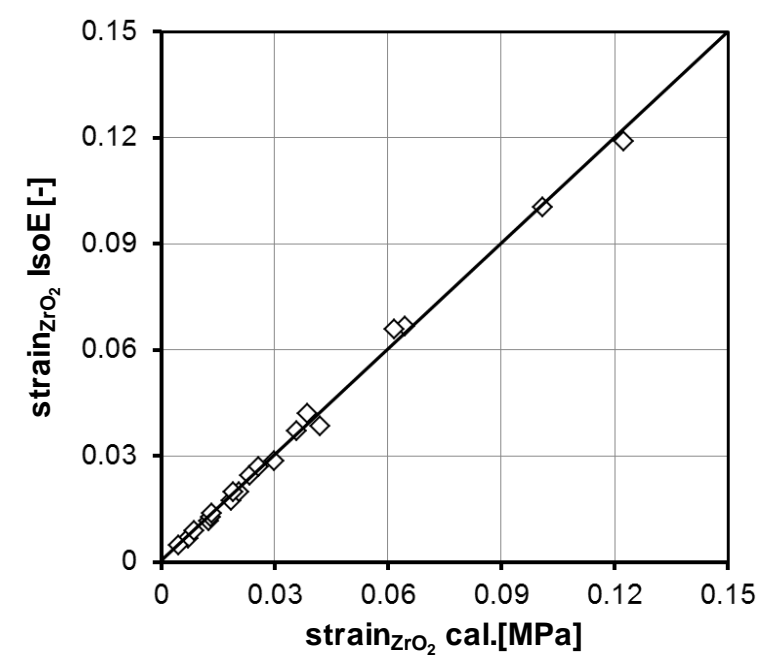

Figure 10. Convergence of the prediction for the local deformation of $\mathrm{ZrO}_{2}$.

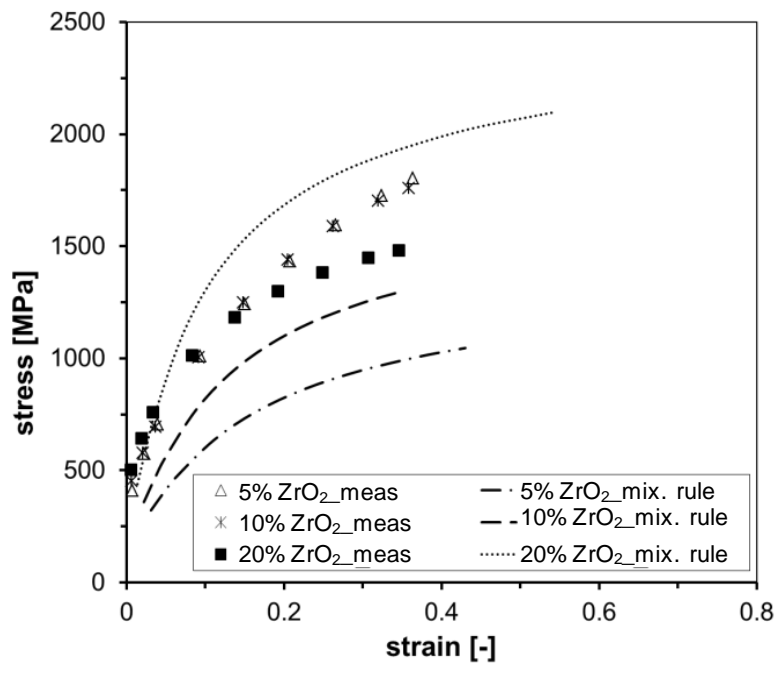

(a)

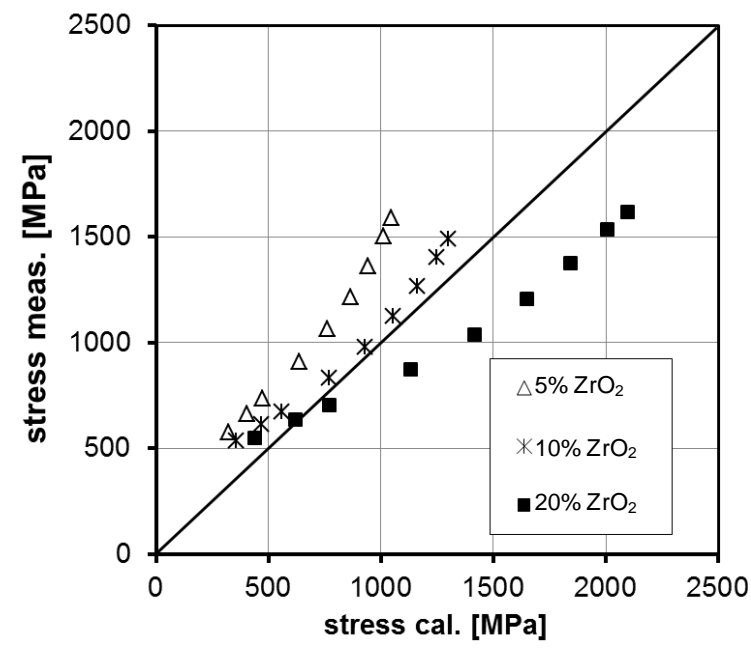

(b)

Figure 11. Predicted stress-strain curves according to the new adjusted method (a) and its convergence with the experiment (b).

Based on the proposed method a graphical working map was developed to predict the values of total strain of composite according to the known values of volume fraction of $\mathrm{ZrO}_{2}$ and of total stress. The working map is shown in Figure 12. The sequence of calculation is as follows:

1) According to known stress-strain curves of the individual phases and their volume fractions the total stress of the composite is determined using Equation (1).

2) By using the lower left corner of the working map and with known values of volume fraction of $\mathrm{ZrO}_{2}$ and of the total stress of composite (see isolines in Figure 12) the local deformation of $\mathrm{ZrO}_{2}$ is determined.

3) By using the upper right corner of the working map and with known values of the total stress of the composite and local deformation of $\mathrm{ZrO}_{2}$ (see isolines in Figure 12) the total strain of the composite is determined.

4) According to the obtained values a stress-strain curve of the TRIP-matrix-composite is predicted.

In Figure 12 an example is illustrated and marked with arrows. For a composite $10 \% \mathrm{ZrO}_{2}$ and a total stress of $900 \mathrm{MPa}$ total strain of the composite $\varepsilon_{\text {mix. }}=0.17$ is determined. On the lower left side the $\mathrm{known} \mathrm{ZrO}_{2}$ content of $10 \%(0.1)$ is used and the total stress gives the value of $\varepsilon_{\mathrm{ZrO}_{2}}=0.03$. On the upper right side the know total stress and the isoline for $\varepsilon_{\mathrm{ZrO}_{2}}=0.03$ is used to find the strain $\varepsilon_{\text {mix. }}=0.17$. 


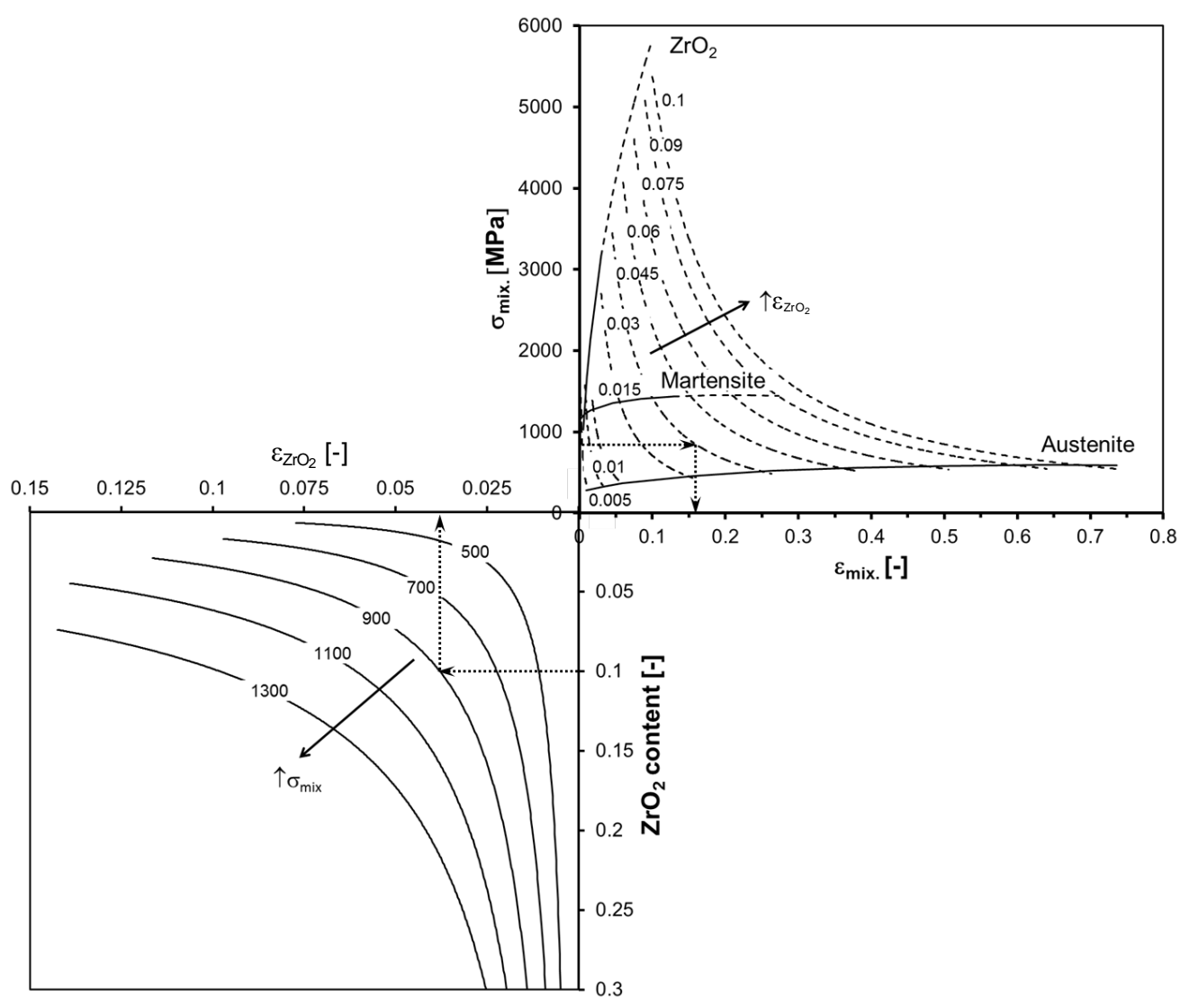

Figure 12. Working map.

\section{Conclusions}

The mechanical behaviour of a TRIP-matrix-composite with the MgO-stabilized $\mathrm{ZrO}_{2}$ content between $5 \%$ and $20 \%$ was investigated in order to predict the stress-strain curves by using the behaviour of the single components of austenite, martensite and ceramic. At various strains the hydrostatic stress in the vicinity of the circumferential surface of the upsetting specimen was measured. Finally, the stress-strain curve of the TRIP-matrix-composite was calculated using the mixture rule, the IsoE-method and a new adjusted method based on the mixture rule. In this calculation, the measured stress-strain curves data of the martensitic condition and of the stable austenite AISI 316L and ceramic $\mathrm{ZrO}_{2}$ were used. The following conclusions can be drawn from the above results and discussions:

- Based on the mixture rule a new method for multiphase materials with more than two microstructure components was developed.

- Comparison of the prediction results with the original method of mixture rule shows significant improvement of the convergence. Furthermore, there is improvement of predicted convergence for large values of the total stress.

- Finally, a working map was designed for a quick graphical definition of the objective functions.

\section{Acknowledgements}

The authors gratefully acknowledge the German Research Foundation (DFG) for supporting the Collaborative Research Center CRC 799 (Collaborative Research Center subproject A6-I).

\section{References}

[1] Schatt, W. (1991) Einführung in die Werkstoffwissenschaft. 7th Edition, Deutscher Verlag für Grundstoffindustrie, Leipzig. 
[2] Fischmeister, H. and Karlsson, B. (1977) Plastizitätseigenschaften grob-zweiphasiger Werkstoffe. Zeitschrift für Metallkunde, 68, 311-327.

[3] Tamura, I., Tomota, Y. and Ozawa, M. (1973) Strength and Ductility of Iron-Nickel-Carbon Alloys Composed of Austenite and Martensite with Various Strength. Proceedings of the 3rd International Conference on Strength of Metals and Alloys, Cambridge, 20-25 August 1973, 611-615.

[4] Karlsson, B. and Linden, G. (1975) Plastic Deformation of Ferrite-Pearlite Structures in Steel. Materials Science and Engineering, 17, 209-219. http://dx.doi.org/10.1016/0025-5416(75)90232-3

[5] Goel, N.C., Sangal, S. and Tangri, K. (1985) A Theoretical Model for the Flow Behavior of Commercial Dual-Phase Steels Containing Metastable Retained Austenite. Part I: Derivation of Flow Curve Equations. Metallurgical Transactions A, 16, 2013-2021.

[6] Bouaziz, O. and Buessler, P. (2002) Mechanical Behavior of Multiphase Materials: An Intermediate Mixture Law without Fitting Parameter. La Revue de Metallurgie, 99, 71-77. http://dx.doi.org/10.1051/metal:2002182

[7] Goureev, D. (2006) Dissertation TU Bergakademie Freiberg.

[8] Wolf, S., Martin, S., Krüger, L., Martin, U. and Lorenz, U. (2012) Mechanical Behaviour of Deformation-Induced $\alpha^{\prime}$-Martensite and Flow Curve Modelling of a Cast CrMnNi TRIP-Steel. Steel Research International, 83, 529-537. http://dx.doi.org/10.1002/srin.201100313

[9] Papaefthymiou, S., Bleck, W., Prahl, U., Acht, C., Sietsma, J. and van der Zwaag, S. (2003) Micromechanical Damage Simulations of TRIP Steels. Proceedings of the International Conference on Processing \& Manufacturing of Advanced Materials, Madrid, 7-11 July 2003, 1355-1361.

[10] Guk, S., Pranke, K., Müller, W. and Yanina, A. (2014) Development of High-Strength TRIP-Matrix-Composite Materials. Proceedings of the International Conference MEFORM 2014: Production and Processing of Clad Materials and Metal Matrix Composites, Altenberg, 26-27 March 2014, 149-159.

[11] Narayanasamy, R. and Pandey, K.S. (1998) Some Aspects of Work Hardening in Sintered Aluminium-Iron Composite Preforms during Cold Axial Forming. Journal of Materials Processing Technology, 84, 136-142. http://dx.doi.org/10.1016/S0924-0136(98)00088-0 
Scientific Research Publishing (SCIRP) is one of the largest Open Access journal publishers. It is currently publishing more than 200 open access, online, peer-reviewed journals covering a wide range of academic disciplines. SCIRP serves the worldwide academic communities and contributes to the progress and application of science with its publication.

Other selected journals from SCIRP are listed as below. Submit your manuscript to us via either submit@scirp.org or Online Submission Portal.
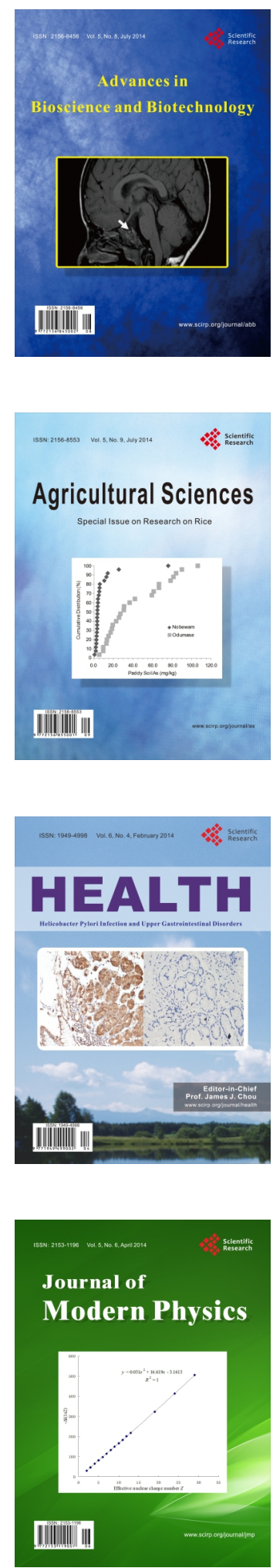
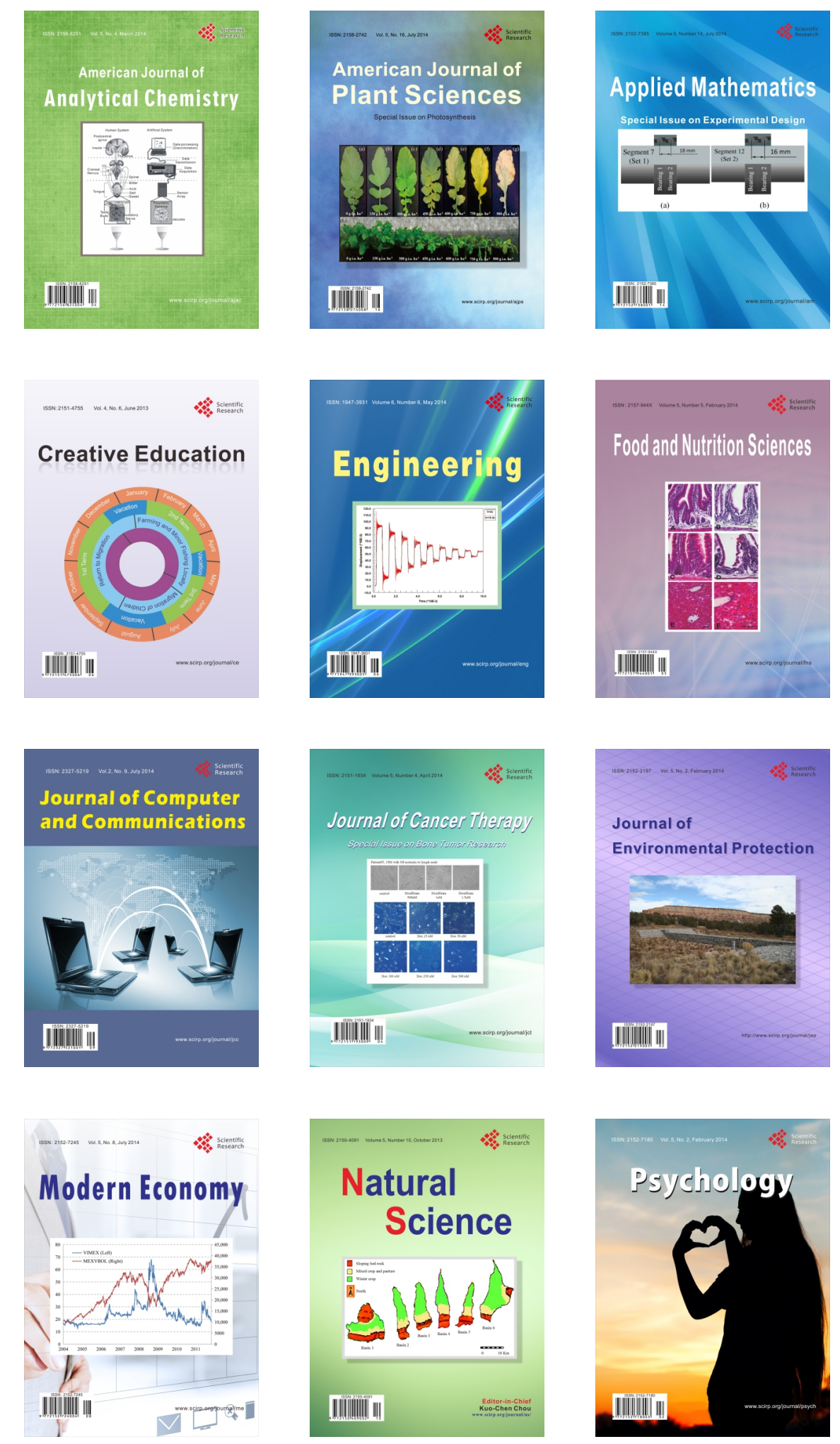